Research Paper Vol 2, No 2, Tahun 2020

\title{
Perancangan Indikator Arus Netral dan Arus Grounding pada Alternator 3 Phase (Studi Kasus Alternator PT Smart Tbk)
}

\author{
Deni Rachmat ${ }^{1}$, Novelita W.Mondamina ${ }^{1}$, Ockri Tamba ${ }^{1}$ \\ ${ }^{1}$ Teknologi Pengolahan Sawit, Institut Teknologi Sains Bandung \\ Jl. Ganesha Boulevard, Lot-A1 CBD Kota Deltamas, Cikarang Pusat, Bekasi \\ Email: deni.rachmat37@yahoo.com
}

\begin{abstract}
Abstrak
Ketidakseimbangan beban listrik 3 phase dari pasokan alternator dapat menyebabkan timbulnya arus mengalir pada penghantar netral (Arus Netral) dan penghantar tanah (Arus Grounding). Arus yang mengalir pada penghantar netral menyebabkan rugi-rugi arus netral dan arus yang mengalir pada penghantar tanah menyebabkan rugi-rugi arus grounding. Penelitian ini adalah merancang suatu alat indikator arus pada penghantar netral sebagai upaya untuk mengetahui dan mengantisipasi adanya arus yang mengalir akibat ketidakseimbangan beban. Rancangan alat ini berlandaskan pada kajian teoritis ketidakseimbangan beban dan pengukuran menggunakan digital clamp meter sebagai data pendukung dan pembanding hasil rancangan alat. Rancangan telah dibuat berupa rangkaian Elektronik Mikrokontroler dengan Sensor ACS712 20A dan trafo arus 30/5A. Setelah dilakukan pengukuran menggunakan Mikrokontroler diperoleh bahwa terjadi ketidakseimbangan beban arus netral 26.85 A dengan losses sebesar 18.02 Watt. Nilai kerugian akibat arus netral Rp. 86.439,75/tahun.dan akibat arus grounding Rp. 3.139,38/tahun.. Error rata-rata pengukuran dengan alat Mikrokontroler terhadap Digital Clamp Meter sebesar $2.63 \%$.
\end{abstract}

Kata kunci: Alternator, ketidakseimbangan beban, arus netral dan grunding, Mikrokontroler Sensor ACS712 20A 


\section{Research Paper Vol 2, No 2, Tahun 2020}

\section{PENDAHULUAN}

Listrik merupakan salah satu kebutuhan pokok yang harus dipenuhi untuk menjalankan berbagai mesin pengolahan di Pabrik Kelapa Sawit (PKS). Kualitas dan kontinuitas pelayanan daya listrik dari alternator sebagai pembangkit listrik dengan penggerak mesin turbin uap/mesin diesel (prime mover) yang tersedia di PKS harus selalu terjamin, dan selalu menghindari terjadinya black out yang dapat menyebabkan berhentinya proses produksi serta kerugian yang cukup besar bagi perusahaan.

Alternator yang digunakan di PKS Sungai Buaya Mill adalah alternator nomor 3 dengan spesisifkasi sebagai berikut: Merk Cummins, tahun pembuatan 2003, Active Power Rated 148 KW, Apperant Power Rated 185 KVA, Rated Current 280 A, Power Factor 0.8, dan Voltage $380 \mathrm{~V}_{\mathrm{L}-\mathrm{L}} / 220 \mathrm{~V}_{\mathrm{L}-\mathrm{N}}$.

Suplai daya listrik 3 phase 1 netral (R, S, $\mathrm{T}, \mathrm{N}), 380$ Volt (line to line), 220 Volt (line to netral), frekuensi 50 Hertz dari alternator dialirkan ke Main Distribution Panel (MDP) untuk selanjutnya dialirkan ke beban (utilitas, mesin-mesin pabrik, dan perumahan karyawan) menggunakan kabel penghantar 4 inti.

Sistem penyaluran daya listrik dari alternator dikatakan seimbang atau simetri jika tegangan tiga phase dan arusnya memiliki amplitudo yang sama dan mempunyai beda phase sebesar $120^{\circ}$ terhadap satu sama lain. Apabila syarat tersebut tidak terpenuhi maka sistem dikatakan tidak seimbang (Unbalanced) [10].

Sistem yang tidak seimbang tersebut dapat menyebabkan arus mengalir pada penghantar netral dan grounding. Pada kondisi setimbang arus yang mengalir pada tiap phase haruslah memiliki nilai yang hampir sama, namun pada kenyataanya sering terjadi ketidakseimbangan beban antara phase satu dengan phase lainnya. Ketidakseimbangan beban disebabkan oleh beberapa faktor, dimulai dari pemakaian beban yang tidak seimbang pada setiap fasa dan gangguan pada salah satu fasa.

Ketidakseimbangan beban dapat mengakibatkan rugi daya listrik, gangguan pada salah satu phasa dalam kumparan alternator dan mengurangi kualitas daya listrik.

Berdasarkan uraian ketidakseimbangan ini perlu dilakukan pengkajian ketidakseimbangan beban guna mengurangi arus pada penghantar netral yang dapat menimbulkan kerugian daya listrik (losses), kajian ini juga diperlukan sebagai data pendukung dalam pembuatan alat pengukur arus netral. Pada penelitian ini dilakukan penambahan indikator arus pada penghantar netral dan grounding guna mengetahui besar arus yang mengalir akibat ketidakseimbangan beban yang terjadi. Oleh sebab itu penelitian ini adalah rancangan indikator arus netral dan grounding pada altenator berdasarkan pada kajian ketidakseimbangan beban tiga phase di Pabrik Kelapa Sawit Sungai Buaya Mill guna mengetahui (indikasi) seberapa besar losses yang terjadi akibat ketidakseimbagan beban.

\section{IDENTIFIKASI MASALAH}

Persoalan penelitian dirumuskan dalam pertanyaan penelitian berikut ini:

1. Seberapa besar ketidakseimbangan beban pada tiap phase pada alternator di Sungai Buaya Mill?

2. Pengaruh yang ditimbulkan akibat beban tidak merata pada di Sungai Buaya Mill ?

3. Seberapa besar losses yang terjadi akibat ketidakseimbangan beban dan seberapa besar losses yang terjadi dengan adanya arus netral dan arus grounding pada sistem pengaliran listrik di Sungai Buaya Mill?

4. Bagaimana rancangan alat pengukur arus netral pada alternator menggunakan sensor ACS712?

5. Bagaimana unjuk kerja alat pengukur arus netral pada alternator menggunakan sensor ACS712?

\section{TUJUAN PENELITIAN}

Tujuan Penelitian sebagai berikut:

1. Mengetahui besar ketidakseimbangan beban tiap phase pada alternator di Sungai Buaya Mill.

2. Mengetahui pengaruh ketidakseimbangan beban yang tidak merata pada alternator di Sungai Buaya Mill

3. Mengetahui losses pada sistem pendistribusian listrik pada sistem penyaluran daya listrik 3 phase

4. Merancang bangun pengukur arus menggunakan sensor ACS712 20A yang berfungsi mengukur arus netral pada alternator di Sungai Buaya Mill

5. Mengetahui unjuk kerja pengukur arus menggunakan sensor ACS712 20A

\section{METODE PENELITIAN}

Pada penelitian ini tahapan-tahapan tersebut ditunjukkan pada gambar 4.1. 


\section{Research Paper Vol 2, No 2, Tahun 2020}

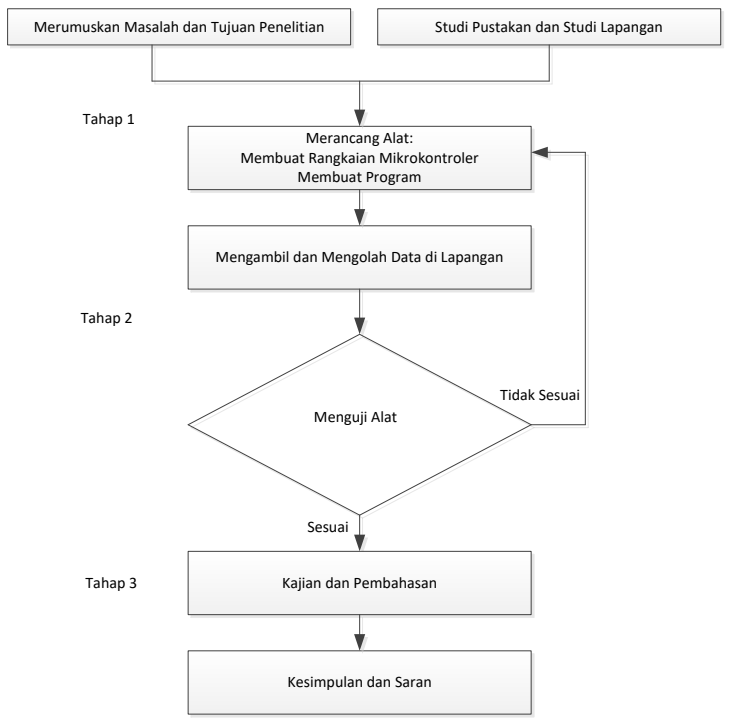

Gambar 4. 1 Tahapan Penelitian

\subsection{Tahap I Studi Awal}

Tahap ini merupakan tahap awal penelitian. Pada tahap ini kegiatan penelitian meliputi, merumuskan masalah dan tujuan penelitian. Pada saat yang bersamaan dilakukan pula studi kepustakaan dan Studi lapangan. Studi kepustakaan bertujuan untuk mendapatkan sumber referensi dan dasar rumusan teoritis yang berkaitan dengan masalah yang akan diteliti untuk selanjutnya dijadikan landasan teoritis dalam melaksanakan penelitian. Studi lapangan bertujuan untuk menentukan lokasi penelitian, pengukuran, kapasitas peralatan terpasang, sistem pembangkitan dan penyaluran daya listrik.

Berdasarkan landasan teori, dan pengukuran dilapangan kemudian dibuat variabel-variabel yang akan diambil data yang berkaitan dengan masalah penelitian.

Variabel penelitian tersebut adalah tegangan listrik, arus listrik, daya listrik, faktor daya,

\subsection{Tahap II Pengumpulan Data \\ 4.2.1 Merancang Alat}

Perancangan alat dalam penelitian ini adalah membuat rangkaian alat untuk mengukur arus dengan menggunakan Mikrokontroler dan membuat kode program, hasil rancangan ini diuji untuk mengukur besar arus netral dan arus grounding, yang selanjutnya dibandingkan hasil pengukurannya dengan Digital Clamp Meter sebagai acuan.

\subsubsection{Data Penelitian}

Data yang diperlukan dalam penelitian ini adalah data primer dan data sekunder. Data primer adalah data yang langsung dikumpulkan dari sumber pertama, sedangkan data sekunder adalah data yang telah tersusun dalam bentuk dokumen-dokumen tertulis. Data sekunder yang diperlukan adalah data spesifikasi peralatan, baik itu peralatan utama maupun peralatan ukur.

\subsubsection{Metode Pengumpulan Data}

Pengumpulan data primer dan data sekunder dilakukan dengan metode wawancara, dan observasi.

\subsubsection{Sampel Penelitian dan Teknik Pengambilan sampel}

Sampel pada penelitian ini adalah mesin pembangkit listrik alternator nomor 5 yang ada di PKS Sungai Buaya Mill.

Teknik pengambilan sampel adalah pengukuran langsung berdasarkan pada variabel-variabel-variabel yang telah ditentukan (Tegangan Listrik, Arus Listrik, Daya Listrik, faktor daya) menggunakan alat ukur yang sesuai dengan spesifikasi alternator di PKS Sungai Buaya Mill.

\subsubsection{Merancang Alat}

Setelah data dari masing-masing variabel ini diperoleh selanjutnya adalah merancang alat yang sesuai dengan data hasil pengukuran. Langkah pertama adalah membuat rangkaian mikrokontroler, selanjutnya membuat kode program, agar besaran-besaran atau variabel tersebut dapat dipahami oleh mikrokontroler. Langkah berikutnya adalah menguji alat tersebut apakah sudah sesuai dengan hasil pengukuran sebelumnya berdasarkan pada masing-masing variabel, jika tidak sesuai langkah kembali ke perancangan, jika sesuai dilanjutkan ke Kajian dan pembahasan dari hasil pengukuran dengan menggunakan alat yang dirancang.

\subsection{Tahap III Kajian dan Pembahasan}

Berdasarkan hasil pengukuran alat rancangan, maka dilakukan kajian untuk menjawab pertanyaan penelitian. Data dari hasil pengukuran diidentifikasi untuk melihat seberapa besar arus netral yang mengalir, seberapa besar losses yang timbul, dan seberapa besar kesalahan pengukuran yang terjadi.

\section{HASIL DAN PEMBAHASAN}

Obyek penelitian dan perancangan alat ini adalah alternator nomor 3 Pabrik Kelapa Sawit di Sungai Buaya Mill

\subsection{Hasil Pengukuran}

Untuk dapat melihat adanya ketidakseimbangan beban maka dilakukan pengukuran pada masing-masing phase. Pengukuran variabel-variabel tegangan listrik, arus listrik, daya listrik, faktor daya dilakukan dalam 4 hari menggunakan alat ukur indikator 


\section{Research Paper Vol 2, No 2, Tahun 2020}

hasil rancangan seperti ditunjukkan dalam tabel 5.1 data hasil pengukuran.

Berdasarkan tabel 5.1 Data Hasil Pengukuran menunjukkan ketidakseimbangan pada masing masing phasanya. Hal ini dapat dilihat dari data yang sudah disediakan, terlihat bahwa besar beban pada phase $\mathrm{R}, \mathrm{S}$, dan $\mathrm{T}$ berbeda antara satu dengan lain, hal ini akan menyebabkan adanya arus netral pada penghantar netral dan juga dapat menyebabkan arus grounding pada alternator. Seperti diunjukan pada data hasil pengukuran dengan menggunakan Digital Clamp Meter dan Mikrokontroler. Dari perhitungan data tersebut arus netral rata-rata yang timbul adalah sebesar $26,85 \mathrm{~A}$.

Dari tabel 5.1 (Lihat lampiran) dapat dibuat skema aliran arusnya seperti ditunjukkan pada gambar 5.1, dapat dilihat bahwa alternator menyuplai beban melalui tiap phase, dengan beban tiap phase seperti yang tertulis dalam skema. Karena beban yang tidak seimbang dan pembagian beban yang tidak merata maka timbul arus netral dan grounding pada alternator

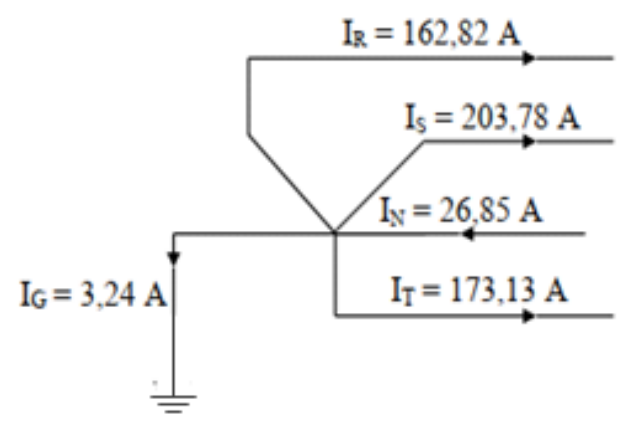

\section{Gambar 5.1 Aliran arus pada alternator}

Dari hasil pengukuran penghantar netral memiliki hambatan $\mathrm{R}_{\mathrm{N}}=0,025 \Omega$ (data hasil perhitungan pengukuran penghantar netral dari altrernator menuju mesin-mesin pabrik), tahanan netral ini dihitung berdasarkan persamaan $R=\rho$. (l/A), dimana $\rho$ adalah hambatan jenis penghantar $(\Omega . \mathrm{m}), 1=$ panjang total penghantar netral (m) dan A luas penampang penghantar $\left(\mathrm{m}^{2}\right)$, sedangkan untuk kawat penghantar groundnya $\mathrm{R}_{\mathrm{G}}=0,063 \Omega$ (data hasil pengukuran).

\subsubsection{Perancangan Alat}

Proses pembuatan proyek akhir alat pengukur arus ini menggunakan sensor ACS712 melalui beberapa tahapan meliputi perancangan rangkaian, pemrograman, dan pembuatan cover pengaman

\section{Perancangan rangkaian}

Rangkaian alat pengukur arus menggunakan sensor ACS712 dapat dijelaskan pada gambar 5.2 pada input arus digunakan current transformer 30/5 A sebagai alat pereduksi arus yang masuk pada sensor, hal ini dikarenakan penghantar netral alternator tidak bisa dihubungkan langsung karena diameter penghantar netral alternator terlalu besar dengan diameter input sensor ACS712. Sebagai pengaman short-circuit dan arus lebih dipasang sikering 5A diantara CT dan Sensor.

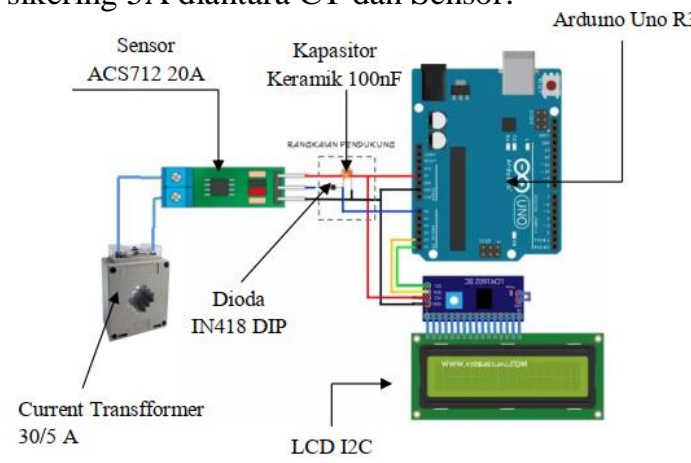

Gambar 5.2 Rangkaian alat ukur

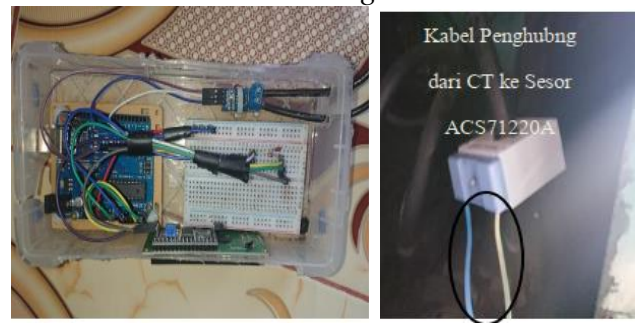

Gambar 5.3 Alat Ukur Mikrokontroler

\section{Pemrograman}

Proses pemrograman bertujuan untuk memberi perintah kepada mikrokontroler untuk melaksanakan tugas sesuai kinerja yang diinginkan.

Berikut merupakan langkah proses pemrograman dalam pembuatan proyek akhir alat pengukur arus netral ini: 1) Membuat program pada software Arduino IDE, 2) Sesuaikan alamat pin-pin komponen yang terhubung dengan Arduino Uno R3 3) Pastikan kode program dapat dijalankan dan tidak error, 4) Hubungkan rangkaian dengan perangkat pemrograman yang berupa laptop 5) Lakukan upload ke Arduino agar program dapat terimpan di memori Arduino 6) Alat telah terisi oleh program dan sudah dapat digunakan. Berikut kode program alat hasil rancangan:

\#include <LiquidCrystal_PCF8574.h>

\#include "ACS712.h"

\#include <Wire.h>

float II;

LiquidCrystal_PCF8574 lcd(0x27); 


\section{Research Paper Vol 2, No 2, Tahun 2020}

ACS712 sensor(ACS712_20A, A0);

void $\operatorname{setup}()\{$

Serial.begin(9600); //baud komunikasi serial monitor $9600 \mathrm{bps}$

lcd.begin(16, 2); //prosedur pemanggilan LCD

lcd.setBacklight(255); //set kecerahan LCD

lcd.setCursor(00, 00); //set pada baris 1 dan

kolom 1

lcd.print("ARUS LINE NETRAL");

//menuliskan "Nama Project"“

lcd.setCursor(00, 1); //set pada baris 2 dan kolom 1

lcd.print("SBYM-PT.SIP"); //menuliskan

"Tempat Pemasangan Project"

delay(2000);

Serial.println("Kalibrasi ... Pastikan tidak ada

arus yang mengalir melalui sensor pada

saat ini");

lcd.clear(); //menghapus data sebelumnya

lcd.setCursor $(03,00)$;

lcd.print("MAGANG ITSB");

delay (5000);

\section{Implementasi}

Berikut langkah-langkah implementasi pemasangan alat: 1) Pemasangan Current Transformer pada penghantar netral Alternator, 2) Pemasangan kabel penghubung antara Current Transformer dengan Sensor ACS712, 3) Pengecekan kecocokan pembacaan alat pengukur dengan digital clamp meter.

Dengan terpenuhinya kebutuhan dan perancangan yang telah dielaskan diatas maka proyek akhir pengukur arus pada penghantar netral dengan menggunakan sensor ACS712 20A diharapkan menjadi alat yang efektif untuk mengetahui besarnya arus yang mengalir pada phase netral dan sebagai alat monitoring pada penghantar netral

\subsubsection{Kajian dan Pembahasan Pembebanan Alternator}

Diketahui

$\mathrm{S}=185 \mathrm{KVA}$,

$\mathrm{I}_{\mathrm{R}}=162,82 \mathrm{~A}, \mathrm{I}_{\mathrm{S}}=203,78 \mathrm{~A}, \mathrm{I}_{\mathrm{T}}=173,13 \mathrm{~A}$,

$\mathrm{I}_{\mathrm{N}}=26,85 \mathrm{~A}, \mathrm{I}_{\mathrm{G}}=3,24 \mathrm{~A}$

V L-L $=380$ Volt, V L-N $=220$ Volt

Maka dengan menggunakan persamaan daya 3

phase dapat dijabarkan menjadi

$S=\sqrt{ } 3 . V . I_{\mathrm{FL}}=185 k V A=\sqrt{3} .380 . \mathrm{I}_{\mathrm{FL}}$

diperoleh

$\mathrm{I}_{\mathrm{FL}}=281,08$ Ampere

Sedangkan perhitungan arus rata-rata dari data pengukuran (tabel 5.1) adalah:

$I_{\text {Rata-rata }}=\left(I_{R}+I_{S}+I_{T}\right) / 3=(162,82+203,78+$ $173,13) / 3=179,91$ Ampere
Jadi persentase pembebanan alternatornya adalah:

$\%$ Pembebanan $=\left(I_{\text {Rata-Rata }} / I_{F L}\right) \times 100 \%=$ $(179,91 / 281,08) \times 100 \%=64,007 \%$

Alternator masih bekerja dibawah batas maksimal pembebanan sehingga masih bisa dilakukan penambahan beban.

\section{Kajian dan Pembahasan Ketidakseimbangan Beban Alternator \\ Ketidakseimbangan beban dapat} diperoleh atau dihitung dari arus yang mengalir pada masing-masing phase ${ }^{[9]}$, sebagai berikut:

$I_{R}=a \cdot I_{\text {rata-rata }}, I_{S}=$ b. $I_{\text {rata-rata }}, I_{T}=c . I_{\text {rata-rata }}$

Maka:

$\mathrm{a}=0,905, \mathrm{~b}=1,132$, dan $\mathrm{c}=0.962$

Pada keadaan seimbang besarnya

koefisien a, b, dan c adalah 1. Dengan demikian rata-rata ketidakseimbangan beban (dalam \%) adalah

$\{|a-1|+|b-1|+|c-1| / 3\} \times 100 \%$ $=8,83 \%$.

Standar international seperti EN-50160 dan IEC 1000-3-series memberikan batasan untuk ketidakseimbangan hingga 2\% untuk Low Voltage dan Medium Voltage ${ }^{[2]}$.

Hal ini menunjukkan bahwa ketidakseimbangan beban sudah melebihi standar, sehingga perlu dilakukan penyeimbangan beban dengan mentransposisikan beban, agar beban tiap phase R, S, T dapat seimbang, menyusun ulang sistem instalasi beban, dan memasang kapasitor kompensasi pada masing-masing phase.

\section{Kajian Losses Yang terjadi akibat} ketidakseimbangan beban pada phase $R, S, T$ Dari tabel 5.1 Data hasil pengukuran, terlihat bahwa besar beban pada phase $\mathrm{R}, \mathrm{S}$, dan $\mathrm{T}$ berbeda antara satu dengan lain dan berbeda pada setiap kali dilakukan pengukuran, oleh karena itu dilakukan perhitungan rata-rata dari setiap pengukuran, perhitungan rata-rata ditunjukkan sebagai berikut:

a. $\mathrm{I}_{\text {rata-rata }}$ Phase $\mathrm{R}=162,82 \mathrm{~A}, \mathrm{~V}_{\text {rata-rata }}$ Phase $\mathrm{R}=393,43 \mathrm{~A}, \mathrm{~S}=\sqrt{3} \cdot 393,43 \cdot 162,82=$ $110,95 \mathrm{kVA}, \mathrm{P}=\sqrt{3}$. 393,43. 162,82. 0,89 $=98,75 \mathrm{~kW}$.

b. $I_{\text {rata-rata }}$ Phase $S=208,78 \mathrm{~A}, \mathrm{~V}_{\text {rata-rata }}$ Phase $\mathrm{S}$ $=393,86 \mathrm{~A}, \mathrm{~S}=\sqrt{3} .393,86.208,78=$ 142,42 kVA, $P=\sqrt{ } 3.393,86.208,78.0,89$ $=126,76 \mathrm{~kW}$.

c. I Irata-rata $_{\text {Phase }} \mathrm{T}=173,13 \mathrm{~A}, \mathrm{~V}_{\text {rata-rata }}$ Phase $\mathrm{T}=393,69 \mathrm{~A}, \mathrm{~S}=\sqrt{3} .393,69.173,13=$ 


\section{Research Paper Vol 2, No 2, Tahun 2020}

118,06 kVA, $P=\sqrt{ } 3.393,69.173,13.0,89$

$=105,07 \mathrm{~kW}$.

Persentase ketidakseimbangan beban rata-rata untuk masing-masing phase diperoleh phase $\mathrm{R}=9,5 \%, \mathrm{~S}=13,2 \%$ dan $\mathrm{T}=3,8 \%$.

Losses rata-rata yang terjadi akibat ketidakseimbangan beban pada masing masing phase adalah:

Phase $\mathrm{R}=9,5 \% .98,75 \mathrm{~kW}=9,38 \mathrm{~kW}$

Phase $\mathrm{S}=13,2 \% .126,76 \mathrm{~kW}=16,73$

$\mathrm{kW}$

Phase $\mathrm{T}=3,8 \% .105,07 \mathrm{~kW}=3,99$

$\mathrm{kW}$

Total losses untuk jaringan 3 phase pada alternator ini adalah $30,103 \mathrm{~kW}$.

\section{Kajian Losses Akibat Adanya Arus Netral Pada Penghantar Netral Alternator}

Dari tabel pengukuran yang sudah dilakukan, losses akibat adanya arus pada penghantar netral trafo dapat dihitung ${ }^{[9]}$.

Kajian ini menggunakan dua input yaitu menggunakan hasil pengukuran dengan alat pengukur mikrokontroler yang sudah dibuat dan menggunakan Digital Clamp Meter:

Pengukuran Arus Netral dengan Digital Clamp meter: $\mathrm{P}_{\mathrm{N}}=\mathrm{I}_{\mathrm{N}}^{2} \cdot \mathrm{R}_{\mathrm{N}}=(26,13)^{2} \cdot 0,025=17,06$ Watt, dimana daya aktif rata-rata alternator $\left(\mathrm{P}_{\text {rata-rata }}\right)$ adalah: $P_{\text {rata-rata }}=S_{\text {rata-rata }} \cos \varphi_{\text {rata-rata, }}$, $\cos \varphi_{\text {rata-rata }}=0.89, \mathrm{I}_{\text {rata-rata }}=179,91, \mathrm{~V}_{\text {rata-rata }}=$ 393,66 maka $P_{\text {rata-rata }}=\sqrt{3} \cdot 179,91.393,66.0,89$ $=109,176 \mathrm{~kW}$. Sehingga persentase losses akibat adanya arus netral pada penghantar netral alternator adalah

$\% P_{N}=\left(P_{N} / P_{\text {rata-rata }}\right) \cdot 100 \%=(0,01706 / 109,176$ $\mathrm{kW}) .100 \%=0,0156 \%$

Biaya losses $=0,01706 \mathrm{~kW} \times 1608$ hours/Tahun $x$ Rp. 2953,63/kWh = Rp. $81025,39 /$ Tahun. Waktu penggunaan alternator $1608 \mathrm{Jam} /$ Tahun sekitar 4 s.d 5 jam, namun pada pelaksaan penelitian ada beberapa pengukuran dilakukan lebih dari 5 jam (untuk memperoleh data acak). Biaya Rp 2953,63 /kWh diperoleh berdasarkan biaya/harga solar area 1 Rp 10337,69/liter dan untuk 1 liter pemakaian solar $3.5 \mathrm{kWh}$ atau $3.5 \mathrm{kWh} /$ liter, sehingga biaya operasional alternator adalah $\mathrm{Rp}$ 2953,63.

Pengukur Arus Netral Dengan Mikrokontroler: $\mathrm{P}_{\mathrm{N}}=\mathrm{I}_{\mathrm{N}}^{2} . \mathrm{R}_{\mathrm{N}}=(26,85)^{2} .0,025 \Omega=18,02$ Watt, dimana daya aktif rata-rata alternator $\left(\mathrm{P}_{\text {rata-rata }}\right)$ adalah: $P_{\text {rata-rata }}=S_{\text {rata-rata. }} \cos \varphi_{\text {rata-rata }}, \cos \varphi_{\text {rata- }}$ rata $=0.89, \mathrm{I}_{\text {rata-rata }}=179,91, \mathrm{~V}_{\text {rata-rata }}=393,66$ maka $P_{\text {rata-rata }}=\sqrt{3} \cdot 179,91 \cdot 393,66.0,89=$ $109,176 \mathrm{~kW}$. Sehingga persentase losses akibat adanya arus netral pada penghantar netral alternator adalah:

$\% P N=\left(P N / P_{\text {rata-rata }}\right) .100 \%=(0,018 / 109,176)$. $100 \%=0,0165 \%$.

Biaya losses $=0,0182 \mathrm{~kW}$ x 1608 hours/Tahun x Rp. 2953,63/kWh = Rp. 86439,75/Tahun.

Selisih perhitungan persentase losses pengukuran arus netral menggunakan Digital Clamp Meter dan Mikrokontroler 0.0009\%

Kajian Losses Akibat Arus Netral yang Mengalir Ke Tanah (Arus Grounding)

Dari tabel pengukuran yang sudah dilakukan (dengan, losses akibat adanya arus pada penghantar ground alternator dapat dihitung besarnya menggunakan persamaan sebagai berikut ${ }^{[9]}: P_{G}=I_{G}{ }^{2} \cdot R_{G}=(3,24 \mathrm{~A})^{2} \cdot 0,063 \Omega=$ 0,661 Watt $=0,000661 \mathrm{~kW}$, dimana daya aktif rata-rata alternator $\left(\mathrm{P}_{\text {rata-rata }}\right)$ adalah: $P_{\text {rata-rata }}=$ $S_{\text {rata-rata }} \cos \varphi_{\text {rata-rata, }} \cos \varphi_{\text {rata-rata }}=0.89, \mathrm{I}_{\text {rata-rata }}=$ $179,91, \quad \mathrm{~V}_{\text {rata-rata }}=393,66$ maka $\mathrm{P}_{\text {rata-rata }}=$ $\sqrt{ } 3.179,91.393,66.0,89=109,176 \mathrm{~kW}$.

Persentase losses akibat adanya arus grounding pada penghantar grounding alternator adalah \% $P_{G}=P_{G} / P \times 100 \%=(0$, $000661 / 109,176) \times 100 \%=0,000575 \%$

Biaya losses $=0,000661 \mathrm{~kW} \times 1608$ Jam/Tahun x Rp. 2953,63/kWh = Rp. 3139,38/Tahun.

\subsubsection{Pengujian Sensor Arus ACS712 20 A}

Sensor yang digunakan dalam rangkaian ini adalah menggunakan sensor arus ACS712 dengan Arus Maksimum yang dapat terukur oleh sensor adalah sebesar 20 A. Pengujian dari sensor arus ini secara keseluruhan dilakukan setelah semua sistem minimum terpasang pada sensor ini. Pengujian dilakukan dengan memberikan tegangan AC pada kaki input pada sensor ACS712.

Pengujian sensor arus ACS712 untuk mendapatkan nilai rata-rata. Data keseluruhan pada sensor ACS712 diambil secara berkala atau sampling dan diolah untuk nantinya dikalibrasi dengan pembacaan arus pada Digital clamp Meter.

Persamaan nilai rata-rata digunakan untuk melakukan perhitungan terhadap sampling yang dilakukan sebanyak 500 kali atau dalam waktu 0.5 detik.Maka data ADC sensor arus selama 0.5 detik akan dibaca dan ADC tersebut dikonversikan kedalam pembacaan tegangan DC.

Sensor arus ACS712 mengeluarkan sinyal analog hasil pembacaan oleh sensor 


\section{Research Paper Vol 2, No 2, Tahun 2020}

secara langsung dan diterima Arduino melalui pin ADC (Analog to Digital Converter) A0.

Selanjutnya dilakukan konversi dari tegangan DC pada sensor arus menjaditegangan AC yang sesuai dengan amperemeter yang terstandar kalibrasi. Alat monitoring ini menghasilkan pembacaan arus aktual dari arus yang mengalir akibat ketidakseimbangan pada alternator. Untuk mengetahui karakteristik pembacaan nilai arus yang terbaca oleh alat monitoring, maka dilakukan perbandingan dengan pembacaan nilai arus yang terbaca oleh Digital Clamp Meter sesuai standar kalibrasi. Kemudian dibandingkan dengan digital clamp meter yang mana berfungsi untuk mengetahui besar error yang terjadi pada alat.

Data kesalahan atau error yang didapat dari tabel pengamatan pada tabel dilakukan perhitungan persentase kesalahan yang didapatkan dengan menggunakan perhitungan persamaan dibawah ini:

$\%$ Kesalahan $=\mid A_{\text {digital clamp meter }}-A_{\text {Mikrokotroler } /}$ $A_{\text {digital clamp meter }} \times 100 \%$

$\%$ Kesalahan $=\left(\sum \%\right.$ Kesalahan $\left./ n\right) \times 100 \%, \mathrm{n}$ merupakan banyaknya pengujian yang dilakukan.

Perhitungan persentase kesalahan pembacaan arus (\% error) terhadap hasil pengukuran Digital Clamp Meter adalah 2.63\%

\subsubsection{Perbandingan Alat Pengukur Arus Netral Dengan Digital Clamp Meter.}

Pengujian sensor Sensor bekerja dengan baik dan dihasilkan nilai rata-rata error sebesar $2.63 \%$ Hasil pembacaan sensor diatas masih terdapat penyimpangan pembacaan dari sensor arus ACS712, hal ini disebabkan dari terbatasnya

sensitifitas atau resolusi pembacaan dari sensor, juga karena terlalu sensitifnya sambungan antar kabel yang apabila bergerak sedikit saja dapat membuat error pembacaan.

PKS Sungai Buaya Mill menggunakan sistem grounding TN-C (Terre-NeutralCombined). Yang mana besar ketidakseimbangan tergolong diatas standard yang sudah ditetapkan oleh IEC $^{[2]}$, maka berdasarkan pernyataan diatas, Sungai Buaya Mill perlu melakukan monitoring arus pada penghantar netral alternator sebagai pengaman, mengingat belum terpasangnya alat monitoring arus pada penghantar netral pada alternator Sungai Buaya Mill. Alat ini cocok dipasangkan pada penghantar netral alternator melihat hasil error alat pengukur terhadap Amperemeter yang sudah terstandarisasi hanya 2,63\%. Berikut grafik pembacaan error alat ukur.

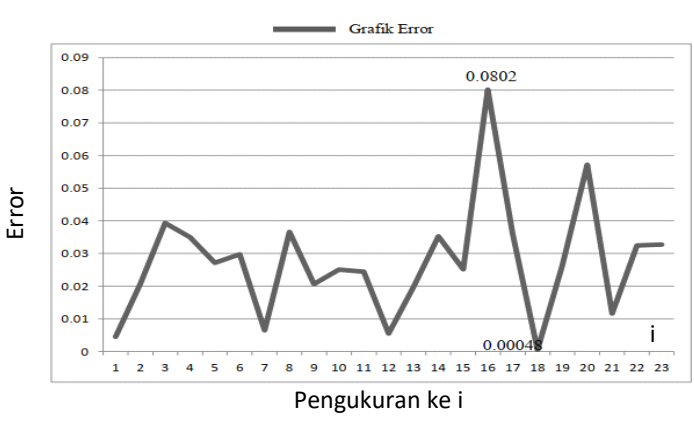

Grafik 5.4 Grafik Error Pembacaan Alat

Dari grafik 5.4 diatas dapat dijelaskan bahwa: 1) Error paling tinggi terjadi pada tanggal 5 Juni 2020 Pukul 05.00 WIB yaitu sebesar $8,02 \%$

2) Error terendah terjadi pada tanggal 5 Juni 2020 Pukul 07.00 WIB yaitu sebesar 0,048\% 3) Rata-rata error pembacaan alat adalah $2,63 \%$

\subsubsection{Perbandingan Biaya Total Alat Ukur Dengan Digital Clamp Meter dan Amperemeter Analog.}

Harga digital clamp meter (DCM) harga Rp.2.465.000,- dengan spesifikasi merk Kyoritsu Kew Snap 2007R dapat mengukur arus hingga 0-600 A (AC), tegangan 0-750 V (AC) dengan limitating error $(1,5 \%+5)$.

Harga alat-alat yang dibutuhkan dengan alat ukur Mikrokontroler dapat dilihat bahwa total pengeluaran yang dibutuhkan adalah sebesar Rp.201.250,00 dan untuk membeli digital clamp meter adalah sebesar Rp.2.465.000,00 yang mana terdapat selisih harga sebesar Rp.2.263.750,00 lebih murah alat ukur mikrokontroler.

\section{KESIMPULAN DAN SARAN}

1. Presentasi ketidakseimbangan beban sebesar $8.83 \%$, maka beban yang disuplai oleh diesel alternator perlu dilakukan penyeimbangan.

2. Persentase rugi-rugi (losses) Alat Pengukur Arus Netral Mikrokontroler adalah 0,128\% atau sebesar 18,02 Watt yang mana apabila dikonversi menjadi rupiah/tahun adalah sebesar Rp. 86.439,75/tahun. Digital Clamp Meter adalah $0,115 \%$ atau sebesar $17,06 \mathrm{~W}$. yang mana apabila dikonversi menjadi rupiah/tahun adalah sebesar $\mathrm{Rp}$ 81.025,39/tahun. Persentase rugi-rugi (losses) akibat adanya arus pada pengantar grounding adalah sebesar $0,000446 \%$ atau sebesar 0,661 Watt yang mana apabila 


\section{Research Paper Vol 2, No 2, Tahun 2020}

dikonversi kedalam rupiah/tahun adalah sebesar 3.139,38/tahun.

3. Pengaruh yang timbul akibat ketidakseimbangan beban pada alternator adalah timbulnya arus netral dengan ratarata sebesar 26,85 A dengan menggunakan alat pengukur arus netral dan 26,13 A dengan menggunakan digital clamp meter dan arus ground.

4. Proses pembuatan alat pengukur arus netral dengan menggunakan sensor ACS712 dikatakan berhasil dan dilalui dengan beberapa tahapan yaitu: a) Perancangan rangkaian b) Pemrograman c) Implementasi.

5. Error rata-rata alat pengukur arus apabila dibandingkan dengan digital clamp meter adalah sebesar 2.63\%, dan apabila dibandingkan dengan amperemeter analog yang banyak digunakan pada PKS Sungai Buaya dengan limitating error sebesar $\pm 3 \%$ (Spesifikasi Tang Ampere Analog Sanwa CAM600S AC) terhadap nilai real arus maka dapat disimpulkan alat yang sudah dibuat dapat digunakan untuk mengukur arus dengan harga alat yang murah.

\section{Saran}

1. Untuk memasang titik sambungan baru pada instalasi listrik harus memperhatikan data-data yang ada, agar dalam pelaksanaan penyambungan, beda pembebanan pada salah satu phase tidak terlalu besar atau menyebabkan losses pada penghantar netral.

2. Melakukan transposisi beban ulang, dengan mengelompokkan pemasangan pada tiap-tiap phasenya dan memperhatikan waktu pembebanan agar tiap phase dapat lebih seimbang.

3. Menambahkan memori eksternal untuk menyimpan data pada alat pengukur arus netral, agar lebih mudah dalam proses monitoring arus yang timbul akibat ketidakseimbangan beban.

4. Stasiun Power House yang biasanya dilakukan pembersihan membuat alat rentan terkena air, sebaiknya alat monitoring arus dibuat agar lebih kedap terhadap air.

5. Penambahan kapasitor kompensasi agar mengurangi losses pada sistem pengaliran listrik.

\section{DAFTAR PUSTAKA}

[1]. Akbar, Rizal (2018), "Rancang Bangun Alat Monitoring Tegangan, Arus, Daya, kWh, serta Estimasi Biaya Pemakaian Peralatan Listrik Rumah Tangga”. Yogyakarta: Universitas Islam Indonesia.

[2]. Arghavani.H, Peyravi.M, (2017), "Unbalanced Current Based Tarrif", paper 0129 CIRED 24 $4^{\text {th }}$ International Conference on Electricity Distribution, Glasgow.

[3]. Ashshiddiqi M.H, Sulo B.D, Minto B," Analisis Pengaruh Beban Tidak Seimbang Terhadap Rele Gangguan Tanah Pada PLN Transmisi APP Malang (Aplikasi GI Sengkaling”), (2019), Voloume 11, No 1 Science Elektro.

[4]. Andalan, (2018), “Karakteristik Sensor ACS7712", www.andalanelektro.id/2018/11/Karakte ristik-sensor-suhu-acs-712/.22 Agustus 2020

[5]. Gunawan, Arif, (2020), "Pahami Perbedaan Genset 1 Phase dan 3 Phase, www.abcpowergenset/pahami-genset-1phase-dan-3-phase/22 Agustus 2020.

[6]. PUIL (2011), Peraturan Umum Instalasi Listrik Indonesia, Jakarta: Badan Standarisasi Nasional

[7]. Pratiwi, Nana, (2017), Tutorial Arduino Mengakses Sensor, www.nyebarilmu/ https://www.nyebarilmu.com/?s=Tutoria $1+$ Arduino+Mengakses+Sensor.

[8]. Simanis, (2019), "Pengertian Pengukuran" www.pelajari.co.id/2019/28/pengertian pengukuran.

[9]. Sogen, Dwiyanto, M., (2018), “Analisis Pengaruh Ketidakseimbangan Beban Terhadap Arus Netral dan Losses Pada Transformator Distribusi di PT. PLN (PERSERO) Area Sorong”, Volume 4 (No 1) Sorong: Politeknik Katolik Saint Paul Sorong.

[10]. Theraja, B.L., A.K (2005), IA Textbook of Electrical Technology Volume I Basic Electrical Engineering, Tarnekar, S.G (Ed). New Delhi: Ram Nagar.

[11]. Zuhal, (2005), "Dasar Teknik Tenaga Listrik” Erlangga, Bandung: ITB. 


\section{JVTI}

JURNAL VOKASI

e-ISSN 2686-3545

TEKNOLOGI INDUSTRI

p-ISSN 2656-6664

\section{Research Paper Vol 2, No 2, Tahun 2020}

VIII. LAMPIRAN TABEL

Tabel 5.1 Data Hasil Pengukuran

\begin{tabular}{|c|c|c|c|c|c|c|c|c|c|c|c|c|c|c|}
\hline \multirow[b]{2}{*}{ Irepl } & \multirow[b]{2}{*}{$\begin{array}{l}\text { PWd } \\
\text { (MIB) }\end{array}$} & \multirow[b]{2}{*}{$\mathbb{R}$} & \multirow[b]{2}{*}{ IS } & \multirow[b]{2}{*}{$\underset{(\text { II }}{\text { II }}$} & \multicolumn{2}{|c|}{$\mathrm{N}($ Aspre) } & \multirow[b]{2}{*}{$\begin{array}{c}16 \\
(1-2 p e)\end{array}$} & \multirow[b]{2}{*}{$\begin{array}{c}\text { IBS } \\
\text { (Na) }\end{array}$} & \multirow[b]{2}{*}{$\begin{array}{r}151 \\
\text { (Nobl) }\end{array}$} & \multirow[b]{2}{*}{$\begin{array}{l}\mathrm{ITR} \\
\mathrm{(Na)}\end{array}$} & \multirow[b]{2}{*}{$\begin{array}{l}1 \mathrm{RN} \\
\mathrm{Nab}\end{array}$} & \multirow[b]{2}{*}{$\begin{array}{l}15 \mathrm{X} \\
\text { (10b) }\end{array}$} & \multirow[b]{2}{*}{$\begin{array}{l}\mathrm{Ins} \\
\mathrm{Cod})\end{array}$} & \multirow[b]{2}{*}{$\cos \mathrm{P}$} \\
\hline & & & & & 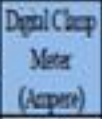 & $\begin{array}{c}\text { Seser } A C S \\
72 \\
\text { (Ampe) }\end{array}$ & & & & & & & & \\
\hline \multirow{8}{*}{$\begin{array}{l}1 / \mathrm{n} \\
2000\end{array}$} & 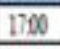 & & & 3.00 & 335 & 3365 & 45 & 392 & 392 & 92 & 234 & 234 & 234 & 085 \\
\hline & 1800 & 186 & 264 & 209 & 33.4 & $\theta$ & 42 & 395 & 390 & 390 & 32 & 282 & 232 & 92 \\
\hline & 1990 & [.] & 173 & 10 & 333 & 13 & 31 & 393 & 39 & 9 & 32 & 18 & 230 & 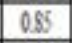 \\
\hline & .000 & 94 & 124 & 88 & 329 & $\infty$ & 51 & 393 & 393 & 93 & 30 & 30 & 232 & 0.88 \\
\hline & 2100 & III & 155 & 1.34 & 302 & 02 & 36 & 385 & 30? & $39 ?$ & 231 & 232 & 231 & 0.9 \\
\hline & 2200 & 173 & 34 & 197 & 399 & 9.76 & 25 & 39 & 34 & $y$ & 32 & 238 & 24 & 0.88 \\
\hline & 2300 & 154 & 53 & 195 & 39 & $\infty$ & 22 & 397 & 39 & 397 & 234 & 232 & $23 !$ & 092 \\
\hline & $\mathrm{N} 90$ & 150 & 213 & 10 & 191 & 198 & 23 & 392 & 92 & 32 & 23 & 24 & 235 & 0.85 \\
\hline \multirow{4}{*}{$\begin{array}{l}3 \mathrm{Jn} \\
3020\end{array}$} & 6500 & 17 & 210 & 182 & 242 & 247 & 38 & 394 & 39 & $39 ?$ & 250 & 230 & 230 & 0.58 \\
\hline & 1600 & 176 & 214 & 175 & 279 & 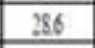 & 21 & 397 & 3) & 397 & 230 & 230 & 27 & 0.58 \\
\hline & 0790 & 127 & 173 & 120 & 246 & 252 & 24 & 395 & 395 & 36 & 232 & 20 & 235 & 092 \\
\hline & 0400 & 15 & 176 & $15 ?$ & 18.4 & & 36 & 393 & 9? & $m$ & 32 & 23 & 230 & 092 \\
\hline \multirow{6}{*}{$\begin{array}{l}5 \mathrm{Ja} \\
0 \times 0\end{array}$} & 650 & 165 & 195 & 171 & 203 & 307 & 29 & 393 & 39 & 393 & 20 & 230 & 232 & 092 \\
\hline & 6600 & 16 & 30 & 14 & 17 & & 23 & 385 & $39 ?$ & 9 & $3 !$ & 232 & $23 !$ & 092 \\
\hline & 0790 & 170 & 306 & 165 & 278 & & 53 & 397 & 234 & & 32 & 28 & 234 & 092 \\
\hline & 1710 & E31 & 145 & 132 & 192 & 2074 & 23 & 397 & 37 & 397 & 234 & 232 & 231 & 092 \\
\hline & 1800 & 19 & 57 & 158 & 205 & 213 & 38 & 39 & 39 & 39 & $3 !$ & 24 & 235 & 092 \\
\hline & 1010 & 18 & 230 & 215 & 307 & & 21 & 394 & $39 ?$ & 9 & 30 & 230 & 230 & 092 \\
\hline \multirow{5}{*}{$\begin{array}{l}\text { Tha } \\
\text { 2000 }\end{array}$} & 1500 & 12 & 175 & 143 & 270 & & 24 & 291 & 38 & 217 & 200 & 250 & 227 & 092 \\
\hline & 1990 & 220 & 28 & 29 & 264 & $279 !$ & 36 & 395 & 35 & 36 & 232 & 230 & 235 & 092 \\
\hline & .000 & 177 & 204 & 197 & 301 & 30 & 29 & 392 & 39? & 392 & 24 & 24 & 234 & 0.85 \\
\hline & 2100 & $1 x$ & 24 & 209 & 28 & & 23 & 393 & 30 & 390 & 232 & 232 & 232 & 09. \\
\hline & 300 & 177 & 304 & 197 & 31.8 & 324 & 53 & 393 & 97 & 39 & 232 & 28 & 230 & 0.85 \\
\hline \multicolumn{2}{|c|}{$8 a-10$} & 1628 & 20037 & 17313 & 26514 & 3285 & 324 & 393.6 & 393.56 & 393.69 & 231.65 & 30.78 & 23182 & 0.89 \\
\hline
\end{tabular}

